\title{
IS THERE A CHILD LABOR TRAP? \\ Inter-Generational Persistence of ChILd Labor in Brazil
}

\author{
by
}

Patrick M. Emerson and André Portela Souza

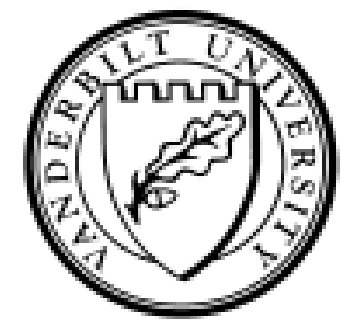

Working Paper No. 02-W14

May 2002

\section{DEPARTMENT OF ECONOMICS \\ VANDERBILT UNIVERSITY \\ NASHVILLE, TN 37235}

www.vanderbilt.edu/econ 


\title{
Is There a Child Labor Trap? Inter-Generational Persistence of Child Labor in Brazil
}

\author{
Patrick M. Emerson \\ Department of Economics \\ University of Colorado at Denver \\ Denver, Colorado 80217 \\ pemerson@carbon.cudenver.edu
}

\author{
André Portela Souza \\ Economics Department \\ Vanderbilt University \\ Nashville, Tennessee 37235 \\ andre.souza@vanderbilt.edu
}

May 2002

\begin{abstract}
This paper examines inter-generational persistence in child labor by developing a dynamic model and exploring its implications empirically in Brazil. We begin by building a simple overlapping generations model of the household child labor decision. We assume that this decision is made by the head of the household, where parents decide to send their child to work only if by doing so the child's contribution to the present consumption of the family outweighs the future consumption benefit the family would enjoy from keeping the child in school. The main predictions of the model are that children are more likely to work when they come from households with parents who were child laborers, from households with parents who have lower educational attainment and that child labor has adverse effects on children's educational attainment and their adult earnings. Evidence of persistence in child labor is found by examining household survey data from Brazil. We exploit the fact that the survey data includes information on child labor of both parents and children in a household, as well as information on the educational achievement of the grandparents. We find that children are more likely to be child laborers the younger their parents were when they entered the labor force and the lower the educational attainment of the parents and of the grandparents. Another important finding is that individuals who start work at a younger age tend to end up with lower earnings as adults suggesting that the vocational training aspect of child labor does not the negative effect from loss of schooling.
\end{abstract}

(JEL classification numbers: J20, O12, O54)

(Keywords: Child Labor, Brazil, Overlapping Generations)

Acknowledgements: For valuable comments and insight would like to thank John Abowd, Kaushik Basu, Francine Blau, Gary Fields, Lawrence Kahn, participants of the Labor Economics Workshop at Cornell University, and two anonymous referees of this journal. This paper has benefited from presentations at El Colegio de Mexico, Universidad de Las Americas, the University of Colorado at Denver, the 2000 Northeast Universities Development Consortium Conference, the 2000 Latin American and Caribbean Economic Association Meetings and the 2001 Royal Economic Society Annual Conference. 


\section{Is There a Child Labor Trap? Inter-Generational Persistence of Child Labor in Brazil}

\section{Introduction}

Child labor is a widespread phenomenon in the world, occurring predominantly in developing countries. Recently, there has been renewed concern about the presence and impact of child labor from politicians, activists and academics alike. Most of the popular discussion has centered on the harmful effects of child labor and ways to curtail its incidence. In economics, much of the recent theoretical literature has focused attention on the fact that the decision to send children to work is most likely made not by the children themselves, but by households who do so out of dire need. ${ }^{1}$

This realization has led to a new way of thinking about the impact of child labor and appropriate policy responses. If it is the head of the household that makes the child labor decision, it raises the possibility that there could be an inter-generational link in child labor. There has been some excellent recent theoretical work examining this link and identifying the potential for inter-generational child labor traps. ${ }^{2}$ In spite of this spate of theoretical work, there is a marked absence of empirical work on the topic.

The present paper is an attempt to examine the inter-generational persistence of child labor empirically by looking at household survey data from Brazil. Previous empirical work on child labor has primarily focused on isolating the determinants of child labor using survey data. ${ }^{3}$ This paper takes a different approach by asking the question: does the child labor status of parents impact the child labor incidence of their children? We look at this question in two ways, our working assumption is that it is income that creates this generational link, but we will later ask if there exists an intergenerational link 
over and above that which is transmitted through income (perhaps through norms). We find strong evidence that this link exists and find that it appears to persist even when income is held constant. Moreover, we find that children who did not work as child laborers command higher salaries later in life, suggesting that the potential human capital gains through apprenticeship as children are outweighed by the human capital gains children receive through schooling.

We begin our examination of the inter-generational persistence in child labor first by building an overlapping generations model of the household child labor decision, and second by examining empirical evidence from Brazil. We try and keep our model as simple as possible and use it to motivate our empirical examination.

In our model, following K. Basu and P. H. Van, ${ }^{4}$ we assume that the child labor decision is made by the head of the household and that parents decide to send their child to work only if by doing so the child's contribution to the present consumption of the family outweighs the future consumption benefit the family would enjoy from keeping the child in school. This is slightly different than Basu and Van's "luxury axiom" where parents send their children to work only if dire poverty forces them to do so. ${ }^{5}$

After constructing the model, we look for evidence of persistence in child labor by examining household survey data from Brazil. We exploit the fact that the data include information on the child labor of both parents and children in a family as well as information on the educational achievement of the grandparents. We find that people who start work at a younger age end up with lower earnings as adults, and that children are more likely to be child laborers the younger their parents were when they entered the labor force, and the lower educational attainment of their parents as well as their 
grandparents. These findings are all consistent with our, as well as many other, models of child labor and poverty persistence.

Perhaps most surprisingly, we find that this inter-generational persistence remains even when we control for household income and parental education. This result suggests that there is a link, beyond what is posited in the model, between the child labor of parents and the child labor of their children.

Together, the model and the empirical results paint a vivid picture of persistence in child labor between generations. The policy implications of these findings are potentially important, for example, it may be that there may be a critical level of resources needed to extract families from the child labor trap, after which no further resources are necessary. This is in contrast to many current policies that suggest the need to make provision for persistent support. As Basu and Van hypothesize, it is quite likely that the poor rely on child labor only to assure survival and, given a choice, would always opt for educating their children. ${ }^{6}$ This paper demonstrates that, if this is the case, the most appropriate policy response may be to concentrate on the condition of each family rather than focusing on individual children.

\section{The Model}

In this section we build a simple model of intergenerational persistence of child labor incorporating the essential aspects of previous theoretical work. The recent theoretical literature on child labor and poverty traps incorporates a set of core assumptions: that parents are altruistic toward their children; that there is a trade-off between child labor and child's human capital accumulation; that the child's human capital accumulation is an increasing function of schooling; and that the credit market is 
imperfect. Using some reasonable characterizations of parental preferences and a child's human capital accumulation, it is possible to generate a child labor trap. We illustrate this possibility by building a simple model that incorporates these four main assumptions. This model is presented to motivate and guide the empirical work that is the main contribution of the paper. We do not test the model directly but rather look for evidence that supports the predictions of the model. This process works both ways however, and we allow our empirical investigation to extend beyond the predictions of the simple model to further enlighten this link and to inform future theoretical work.

We begin with a simple model where each family consists of one adult and one child. The adult values both current consumption and the educational attainment of the child. Educational attainment as a child determines the wage earnings of the adult. A child can go to school and/or work. The amount of time spent working detracts from the total educational attainment of the child and thus diminishes the child's earnings once he/she reaches adulthood. Therefore families with little education are more desperate for the contribution to current consumption the child can provide through work than are families with high education and, thus, it is the low education families that will send their children to work while high education families will not.

Consider a household that consists of two agents in each period: an adult and a child. Each agent lives for two periods (child and adult), and upon reaching adulthood each agent creates a child, making this a standard overlapping generations model. All adults are identical, as are all children. There is no population growth and we shall normalize the total population to the unit interval. We assume that the adult in each period makes the decision of whether or not to send the child to work (and thus forgo at least some of the child's education). ${ }^{7}$ In addition, total human capital accumulation (from 
total education as a child) is the sole determinant of adult wage. We shall normalize the child wage to 1 and assume this to be the same as the wage for an adult worker with no education.

We shall first present the general model and, later, a specific model with an analytic solution. Here, however, we consider the household's child labor decision and describe situations in which a child labor trap can arise. ${ }^{8}$

In each period the adult's utility is given by the function:

$$
U_{t}=U\left(c_{t}, h_{t+1}\right)
$$

where $c_{t}$ is the period t consumption of the family and $h_{t+1}$ is the human capital achievement of the child. Thus the adult cares about the education of the child in and of itself. $^{9}$

Adults are endowed with one unit of time in each period. As adults, all of the agent's time is spent working and earnings are given by the production function:

$$
w_{t}^{a}=h_{t}
$$

where $w_{t}^{a}$ is the income of the adult and $h_{t}$ is the stock of human capital of the adult. ${ }^{10}$ The young are also endowed with one unit of time, which can be divided between schooling and work. By assumption, the child wage is normalized to 1, so a child who spends all of his or her time working will earn $\$ 1$. The child's production function is:

$$
w_{t}^{c}=1-e_{t}
$$

where $w_{t}{ }^{c}$ is the earnings of the child in period $\mathrm{t}$, and $e_{t}$ is the time spent in school, and $e_{t} \in[0,1]$. Total family earnings at time $\mathrm{t}$ is thus given by:

$$
W_{t}=w_{t}^{a}+w_{t}^{c}
$$

The budget constraint for the family is: 


$$
c_{t} \leq W_{t}
$$

which will bind by non-satiation as long as the marginal utility derived from increased consumption is always greater than zero.

We assume that there exists a technology that converts education as a child into adult human capital, or:

$$
h_{t+1}=f\left(e_{t}\right)
$$

where $f(0)=1, f(1)=\bar{h}>1$, and $f^{\prime}\left(e_{t}\right) \geq 0$ for all $e_{t} \in[0,1]$.

We can substitute the constraints into the objective function (1) and derive the adult's problem:

$$
\max _{\left\{e_{t}\right\}} U\left(h_{t}+1-e_{t}, f\left(e_{t}\right)\right) .
$$

Let $e^{*}$ be the solution to the adult's problem. We can now express the optimal education level of the child as a function of the adult's human capital:

$$
e^{*}=g\left(h_{t}\right),
$$

where $g(\cdot)$ depends on the functional forms of $U(\cdot)$ and $f(\cdot)$. The law-of-motion is then:

$$
h_{t+1}=f\left(g\left(h_{t}\right)\right) \equiv \Phi\left(h_{t}\right) .
$$

Depending on the functional forms of $f(\cdot)$ and $g(\cdot)$, the $\Phi(\cdot)$ function can take on many different shapes. One such possible shape is of the type illustrated in Figure 1 (where $f^{\prime}(\cdot)$ and $g^{\prime}(\cdot)$ are positive). This is a case where a child labor trap can arise. Here there are multiple steady-state equilibria; two stable and one unstable. One stable equilibrium exists at $h_{t}=1$ and the other at $h_{t}=\bar{h}$. The unstable equilibrium is at $h_{t}=h^{*}$. In fact $h^{*}$ is a critical value of human capital attainment for when the adult's human capital is below $h^{*}$ the child will end up with even less human capital until the family reaches the steady state of $h_{t}=1$, where the children do nothing but work. Alternatively, 
if the adult's human capital is above $h^{*}$, the child will end up with more human capital than the adult and the family will eventually reach the steady state of $h_{t}=\bar{h}$, where the children do no work and attend school full-time.

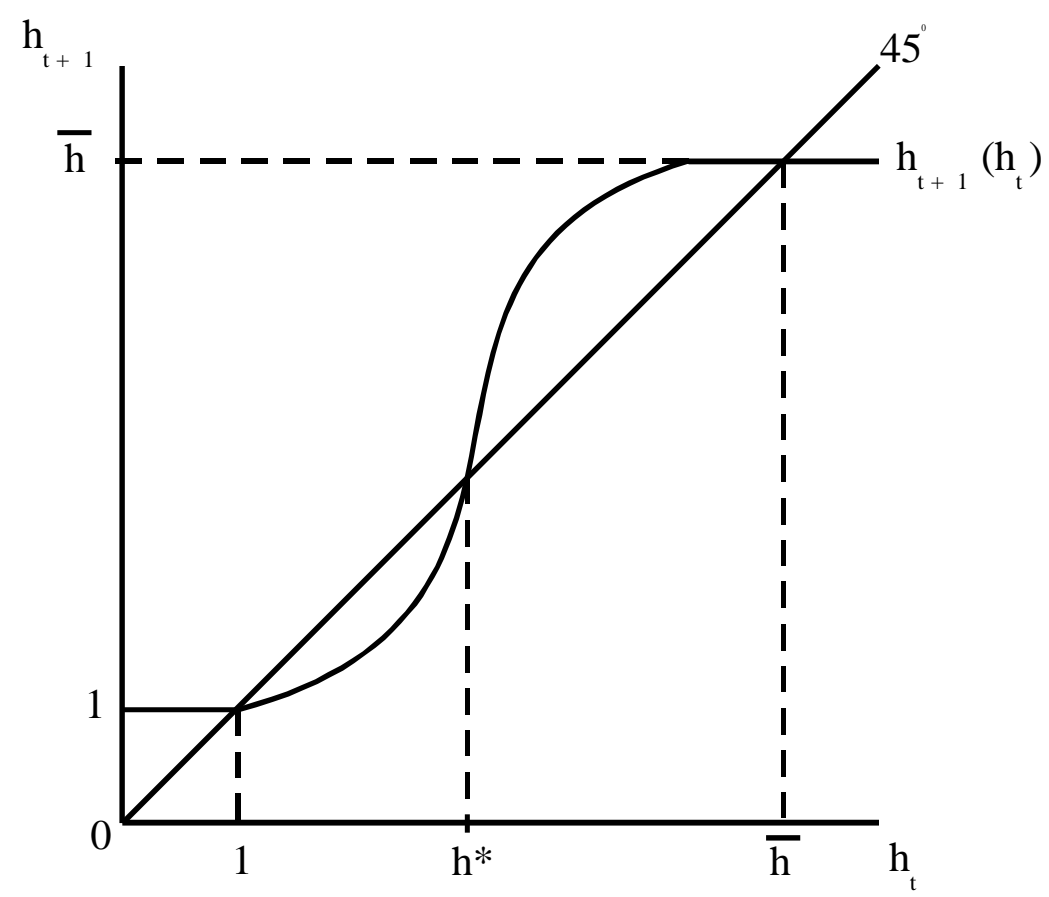

Figure 1: The $\mathbf{h}_{t+1}$ Function

It is important to note that this model implicitly assumes that there is no access to capital markets for these families (i.e. they cannot borrow against the future earnings of the children) and that there is no uncertainty in this economy. Efficient credit markets can alleviate the tension in this model between current consumption and children's human capital and in general can have important mitigating effects on child labor as shown in P. Ranjan. ${ }^{11}$ Again, our attempt is to describe as simple a model as possible, 
but capital markets available to the poor of the developing world are generally considered, at best, imperfect, and uncertainty would not alter the main results of the model.

As a concrete example that gives rise to the type of shape of the $\Phi(\cdot)$ function illustrated above, a specific case is given below.

Consider a utility function of the Cobb-Douglas type:

$$
U\left(c_{t}, h_{t+1}\right)=c_{t}^{\alpha} h_{t+1}^{1-\alpha}, \quad \alpha \in(0,1),
$$

where (2), (3), (4) and (5) are all the same as given above. The parameter $\alpha$ in this function represents the relative weight the family places on current consumption and the child's human capital attainment. Now suppose that the returns to education are 'lumpy.' For example, there may be discrete jumps in the returns to education when a person reaches the stages of literacy, primary education, secondary school diploma, etc. ${ }^{12}$ For simplicity, we assume a polar case where the returns to education are zero unless the child spends all of his or her time in school (perhaps until the end of secondary school). In reality there are likely to be many intermediate levels, but as long as discrete jumps exist, the analysis will be essentially the same, but intermediate equilibria could arise. In this case, we assume that possessing a secondary school diploma allows an individual to command a much higher wage than a person who has completed virtually as much schooling but who does not possess a diploma. We can capture this idea with a new technology that converts education into adult human capital in the following way:

$$
h_{t+1}=\left\{\begin{array}{lll}
\Theta, & \text { if } & e_{t}=1 \\
1, & \text { if } & e_{t}<1
\end{array}\right.
$$

where $e_{t} \in[0,1]$, and $\Theta>1$. $\Theta$ can be interpreted as returns to education or simply as the educated adult wage rate. This illustrates the polar case where an adult who does not 
have a secondary school diploma commands a wage of 1 , the same as a child laborer. This polar case is considered to simplify the analysis. Note that in this case, no one will select a level of education between 0 and 1 because education is costly.

We can solve this problem analytically as the adult's decision is now a binary one: send the child to school or to work. The adult will send the child to school $\left(e_{t}=1\right)$ if and only if:

$$
U_{t}^{e_{t}=1} \geq U_{t}^{e_{t}=0}
$$

After plugging in the budget constraint (and noting that non-satiation holds with this utility function), this decision rule becomes:

$$
U_{t}^{e_{t}=1}=\left(h_{t}\right)^{\alpha}(\Theta)^{1-\alpha} \geq\left(h_{t}+1\right)^{\alpha}(1)^{1-\alpha}=U_{t}^{e_{t}=0} .
$$

Which reduces to:

$$
h_{t} \geq\left[\Theta^{(1-\alpha / \alpha)}-1\right]^{-1} \equiv h^{*} .
$$

So (12) defines the critical value $h^{*}$ where adults that have human capital $h^{*}$ and above will send their children to school full time and those that do not will send their children to work full time. Thus there are two steady-state equilibria in this model, at full education and at no education. This is illustrated in Figure 2. 


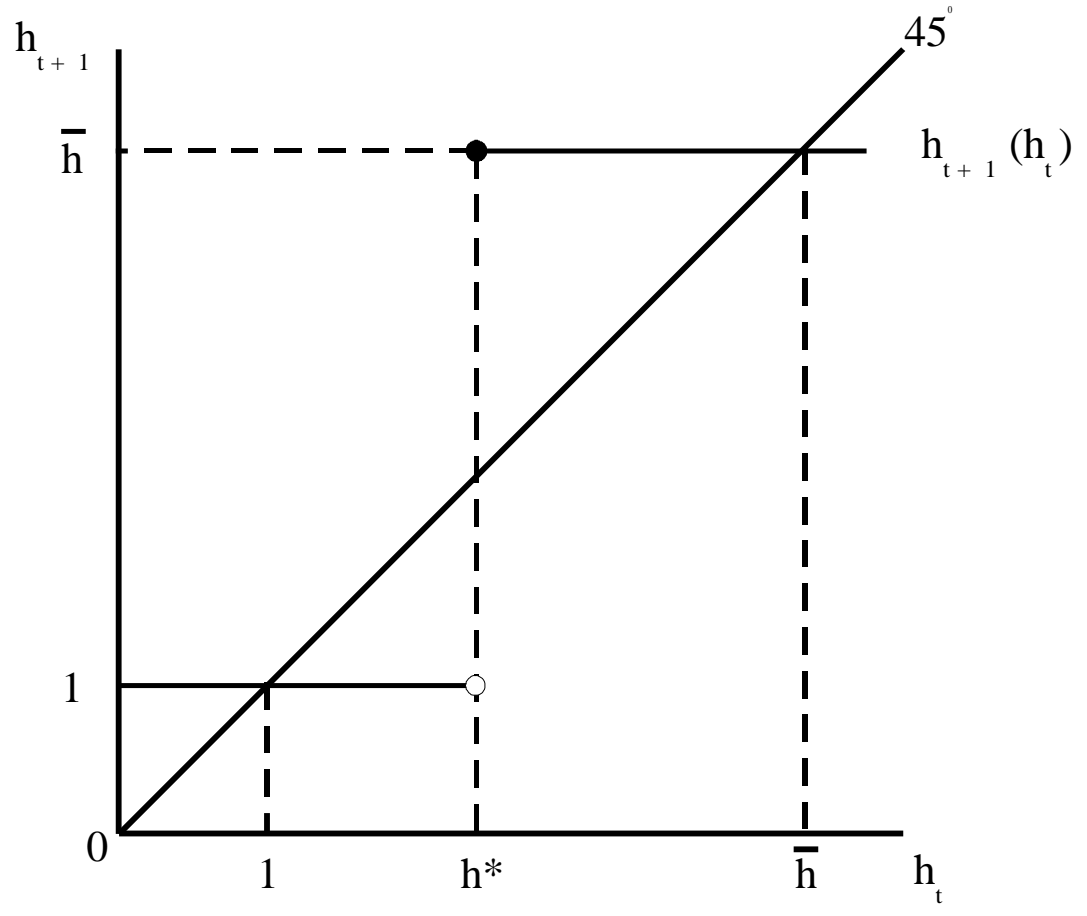

\section{Figure 2: The $\mathbf{h}_{t+1}$ Function with Discrete Returns to Education}

For a wide range of parameterizations, $h^{*} \in(1, \Theta)$. For example if $\Theta=1.75$ and $\alpha=0.5$, then $h^{*}=1.33 \overline{3}$. It is also interesting to note that $h^{*}$ is increasing in $\alpha$, and decreasing in $\Theta$. Thus the more weight the adults places on current consumption as opposed to the child's human capital achievement, the more likely the adult is to make the choice of zero education. In addition, the higher the returns to education, the more likely the adult is to make the choice of full education.

While this specific model is a polar version of the returns to education or the child labor choice, we believe it illustrates well the fundamental inter-generational link between child labor of the parents and their offspring. This is the link that we explore empirically in the next section and this model serves as a guide for our empirical investigation. 


\section{Empirical Evidence from Brazil}

\subsection{The Data}

The data used in this study come from the 1996 Brazilian Household Surveys called Pesquisa Nacional por Amostragem a Domicilio (PNAD) conducted by Instituto Brasileiro de Geografia e Estatística (IBGE), the Brazilian census bureau. It is an annual labor force survey much like the Current Population Survey in the U.S. Covering all urban areas and the majority of rural areas in Brazil (with the exception of the rural areas of the Amazon region), the sample is based on a three stage sampling design. With the exception of the first stage, the sampling scheme is self-weighted and the sampling varies across regions and over time. The 1996 PNAD encompasses approximately 85,000 households.

The sample selection of this study consists of individuals between 10 and 14 years old that are considered a son, daughter or other relative in the family unit. ${ }^{13}$ There are 36,975 observations for children in this age cohort. Each observation consists of information on the child characteristics, his or her parent characteristics and his or her family characteristics. Since we are primarily concerned with the impact of parent's child labor status on the child labor status of the children, we use a sample of observations with complete information of the father's and the mother's characteristics. Due to this

criterion, families with single heads are excluded from the analysis. ${ }^{14}$ Finally, all observations for which the age difference between the head of the family or spouse, and the oldest child is fourteen or below, are excluded as well. Excluding the above observations reduced our sample by 8170 to 28,805 , or 22 percent.

The child labor variable for the children is constructed as follows: A child is considered working if he or she worked on the labor market any strictly positive hours 
per week. ${ }^{15}$ To check the robustness of our results we estimated the same models using an alternate definition of child labor: if he or she worked 20 hours or more on the labor market per week. The results using this alternate definition are qualitatively the same and are not presented here but are available upon request.

The child labor variable for the parents is defined as follows. The PNAD survey asks each individual the age at which he or she started to work. A parent who responded that they began working in the labor market at 14 years old or below is considered to have been a child laborer. We also used an alternate definition where we consider an adult to have been a child laborer if they entered the labor force at age 10 or below to check the robustness of the results and to account for any generational differences in child labor norms. As with the child's child labor variables, the results for the estimation with this alternate definition are qualitatively the same and are available upon request.

For each child, we also obtained his or her school attendance status, gender and region of residence. Similarly, we constructed years of schooling, age and employment status of the parents. The basic statistics of all the variables used in this analysis are presented in the Appendix. ${ }^{16}$

Table 1a presents the proportions of child labor and adult's child labor status in 1996 for the base-line definitions of child labor for the children and parents. In Table 1a, of all 10 to 14 year old children in the sample, 13.9 percent worked in the labor market. 70.6 percent of their fathers were child laborers and 37.2 percent of their mothers started working at age 14 or below. More importantly, of all children belonging to a family in which the father was a child laborer, 17.3 percent are child laborers. On the other hand, of all children coming from a family in which the father was not a child laborer, only 5.9 percent are child laborers. Similarly, of all children that belong to a family in which the 
mother was a child laborer, 24.3 percent are child laborers. Of all children coming from a family in which the mother was not a child laborer, around 7.8 percent are child laborers. Note that 67.8 percent of children who are not child laborers have fathers who were (and 32.7 percent have mothers who were). This reflects the fact that the child labor market participation rates in Brazil have been falling through time since at least 1950.

Tables $1 \mathrm{~b}$ and $1 \mathrm{c}$ present similar figures for daughters only and sons only, respectively. For female children aged ten to fourteen in our sample, 8.7 percent are child laborers, while that figure is 19.1 percent for male children. From Table $1 \mathrm{~b}$ we can see that, in terms of unconditional probabilities, a daughter whose father was a child laborer are approximately eight times more likely to be a child laborer compared to a daughter whose father was not a child laborer and more than twice as likely to have a mother who was a child laborer. For sons, as shown in Table 1c, these figures are approximately three and four times, respectively.

Although these figures are unconditional probabilities, they suggest the existence of inter-generational persistence in child labor in Brazil.

\subsection{Empirical Models of Inter-Generational Persistence of Child Labor}

To test the inter-generational effect of child labor we estimate two different models. The first is a probit model of the child labor indicator variable on parents' child labor status and a vector of other controls. The second is a Cox proportional hazard model of number of years between birth and the age at which the child entered the labor force on the parent's child labor indicator variable plus a set of control variables. The empirical literature on child labor emphasizes the fact that the child labor decision is in fact a joint child labor and school attendance decision. ${ }^{17}$ In order to account for this 
decision structure, we additionally estimate three different models, each of which depend on the assumptions on the decision making process. We estimated a sequential probit model, following Grootaert and Patrinos, in which the school versus work decision is assumed to be sequential. ${ }^{18}$ We also estimated a multinomial logit model and a bivariate probit model that assume that the decision is made on all of the options simultaneously. Given that we are primarily concerned with the persitence of child labor, and that the main results hold for all models, we will present the first two models only. We believe that the two models presented below are sufficient evidence to support our main hypothesis. However, the results for the other three models support our findings from the probit and Cox models and are available upon request.

\subsubsection{The Probit Model}

To estimate the effect of parental child labor on the incidence of work among youths aged 10-14, we first estimate a standard probit model. ${ }^{19}$ The dependent variable is an indicator that equals one if the child usually works any strictly positive hours in the labor market. This is regressed on indicator variables that equal one if the child's mother and father were child laborers (began working at age 14 or below). Also included are the age of the child, the age of the parents, the number of brothers and sisters aged 0-5, 6-9, 10-14 and 15-17, and indicators for if the child is female, lives in an urban area, has a father that is not in the labor market, has a mother that is not in the labor market. ${ }^{20}$ The results are shown in the first column of Table $2 .^{21}$

We find that parental child labor has a strong and positive effect on the probability that a child is in the labor force. Moreover, a female child and children in urban areas are less likely to work in the labor market. Also, the greater the number of 
siblings aged 5 to 14 , the more likely the child is to work. Children are also less likely to work if either parent is not in the labor market. ${ }^{22}$

If the child labor trap explanation outlined in the model is the only determinant of the intergenerational persistence of child labor, then the parental child labor effect should vanish when one controls for family wealth or any appropriate proxy for it. One such potential proxy is the education of the parents.

Column three shows the results of the regression added the parent's years of schooling as dependent variables. As expected, the years of schooling of the parents have a strongly negative and significant effect on the child's probability to work. These results indicate that a child is more likely to be a laborer if his/her parents were child laborers and less likely the more educated are his/her parents. Note, however, that the effect of parental child labor remains positive and statistically significant.

In order to evaluate the impact of the grandparents' education on child labor status of the grandson or granddaughter and to possibly enhance the proxy for family permanent income, we also estimate a probit model that include the years of schooling of grandparents as explanatory variables. ${ }^{23}$ Column 5 of Table 2 shows the coefficients from the complete set of regressors. When we include the parents' education variables, the years of schooling of grandparents becomes insignificant. These results suggest that there is no direct link between grandparents' education and child labor status of the grandchild. Although not reported, we estimated a probit including grandparents' years of schooling but excluding the parents' years of schooling variables. In this case, the grandparents schooling variables became significant. Thus, the schooling effect appears to operate through the education of the parents only. Note that the coefficients on the number of brothers agend 10-14 and on the number of sisters aged 10-14 are no longer 
significant, which could be due to correlation between grandparents education and family size.

Adding income of the family in our probit specification is likely to suffer from an endogeneity problem, but considering it as an explanatory variable is useful for it can help determine if education of the parents is just a proxy for permanent family income. The income of the family minus the income from all children is included in the regressions in Table 3. The first specification includes both the family income variable as well as the parents' education variable. The results of this regression are given in the first column of Table 3. In this case, the coefficients on both parents' child labor indicator variables are positive and significant and the coefficients on the parents' education variables are negative and significant. The coefficient on the family income variable is not significant, however. In the second specification, shown in column three of Table 3, the schooling of the parents is not included. Here, the coefficients on the parents' child labor indicator variables are still positive and significant but now the coefficient on the family income variable is negative and significant.

These results are unexpected and quite striking. For it appears that there is an effect of parents' child labor variable over and above that of the effect on family income and parental education. These results are not predicted by our simple model and suggest that the effects of parental child labor may be more complex than the simple human capital relationship posited in our model. This suggests that future research is needed to shed more light on this aspect of child labor. For example, it could be that human capital accumulation is not only determined by the amount of education, but by the quality of education, the level of education of siblings, the household environment, etc. 


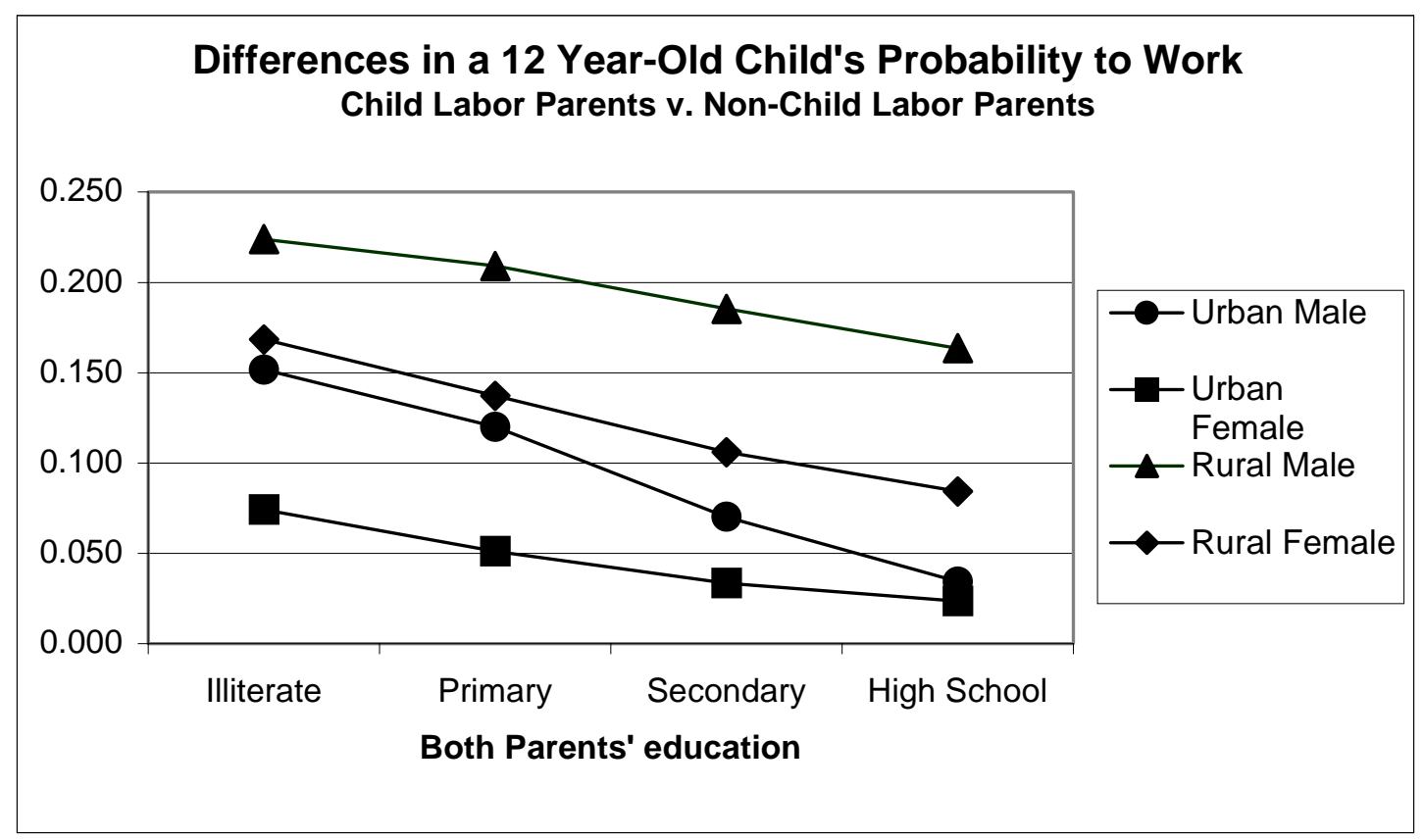

Figure 3: Effect of Education on the Inter-Generational Persistence of Child Labor

Nonetheless, the results suggest that there is indeed a 'family wealth effect' on child labor. To illustrate the interaction between parental child labor status and their educational achievement, Figure 3 presents the difference in the probability of working in the labor market for a 12 year-old child coming from a family with parents who were child laborers, compared to a family where parents were not child laborers. It is assumed that both parents have the same level of education, that they are both in the labor market, forty years old and have only one child. The probability differences are constructed for sons and daughters in rural and urban areas separately, and use the coefficients from the first column of Table 2. Notice first that, for any level of parental education, a child that belongs to a family with parents who were child laborers is more likely to be a child laborer. Second, this difference decreases as the education level of the parents increases. This is exactly what we would expect from our child labor trap hypothesis. 


\subsubsection{The Cox Proportional Hazard Model}

An alternate way to evaluate the inter-generational persistence of child labor is to estimate a Cox proportional hazard model of the number of years between birth and the age at which the child entered the labor market. ${ }^{24}$ This model accounts for the fact that we have censored observations in our data set. These censored observations come from the fact that households are sampled once and at that time children are asked if they are active in the labor market. Consider an 11-year-old child that answers no. He or she is considered not to be a child laborer in our estimation, even though he or she may enter the labor market the next day. By lumping all children aged 10 to 14 who answer no together in one category, we are not accounting for the fact that many of the children will enter the labor force before the age of 14, which we do not observe. The Cox hazard model allows us to account for exactly this problem.

In order to estimate a hazard model, it is necessary to create the duration variable. In our case, this variable is uncensored for those children that started working at age 14 or below and right-censored for those children who have not started working yet. We obtain this variable by assigning the age the child started working for those active children, and assigning the age of the child itself for those children that are not in the labor market. ${ }^{25}$ Our explanatory variables in this model are the same as in the probit model from the previous section, except that we exclude the child's age.

The Cox hazard model answers a slightly different question then the probit model above. Whereas the probit model concerns the probability that children will be child laborers, the Cox model concerns the likelihood that children will enter the labor force earlier in life. We expect that, ceteris paribus, the parents having been child laborers 
increases the likelihood that the child will enter the labor force earlier in life. We also expect that the more years of schooling the parents have, the less likely the child will enter the labor force earlier in life.

The survival function for the model is shown in Table 4 and results of this model are shown in Table 5. In Table 5, as expected, the child labor incidence of both parents increases the probability of the child entering the labor force at a younger age. And these results hold even when we control for parental schooling. Again, the more years of schooling for both parents decreases the probability of the child entering the labor force at a younger age. Also, girls are less likely to enter the labor force earlier (outside the home) than are boys, and urban children are less likely to enter the labor force earlier than are rural children. Once more, the grandparents' years of schooling do not affect the probability the child enters the labor force earlier, as revealed by the last two columns of Table 5. The results from this Cox proportional hazard model are qualitatively similar to the results of the probit estimation given in Table 2.

\subsection{The Cost of Child Labor}

So far we have shown strong evidence of inter-generational persistence of child labor in Brazil. However, in order to explain why we should be concerned with the incidence of child labor, it is important to look at the economic consequences of child labor in a person's life. One main negative effect of child labor is the potential for child labor to hamper the ability of the adult to generate higher earnings.

In order to assess the impact of having been a child laborer on current earnings, we estimate both a simple OLS regression and a Heckman selection model for both mothers and fathers in the sample. In these specifications we regress the log of current 
earnings on age and age squared, age they started work and its square, the grandfather's years of schooling, the grandmother's years of schooling and a race indicator variable. In addition, in separate specifications, we add the individual's years of schooling. For the selection-bias corrected estimations we add the number of sons and daughters aged zero to nine years old in the first stage regression. The results are given in Table 6.

For both fathers and mothers, the coefficient on the age they started work is positive and significant in all specifications. In the specification that excludes the years of schooling variables, the age started work coefficients can be interpreted as the forgone earnings of an individual entering one year earlier in the labor market. Moreover, child labor has a negative impact on current earnings even when we control for education and other variables. This means that there are negative aspects of having been a child laborer over and above that of loosing out on education. Therefore there do not appear to be positive effects on adult earnings of gaining work experience as a child laborer. The squared term is negative and significant, meaning that the marginal negative impact of child labor for adults lessens the later the individual enters the labor force.

\section{Conclusion}

This paper presents an overlapping generations model of inter-generational child labor persistence and finds strong evidence of such a link in Brazil. The results suggest that there is a significant relationship between a parent's child labor incidence and years of schooling, and those of their children. We find that children are more likely to be child laborers if their parents were as well. In addition, we find that children are less likely to be a child labor the more educated their parents are. Moreover, the educational attainment of grandparents does not directly affect the child's labor status, but there 
seems to be an indirect impact that is transmitted through the parents' education. These results hold when we control for family income as well. Additionally, earnings as an adult are lower, ceteris paribus, the earlier the individual enters the labor market. Together, these results paint a striking picture of the inter-generational persistence and the harmful effects of child labor within families.

Surprisingly, there appears to be an inter-generational effect of child labor over and above that which is transmitted through household income and parental education. This result suggests that richer models are needed with a more sophisticated view of the household child labor choice that accounts for this aspect of persistence. On one hand, if this result comes from some unobservable human capital characteristic that is captured by the parents' child labor variables (e.g., school quality), then our finding is essentially capturing the intergenerational poverty persistence and thus it is consistent with our child labor trap model. On the other hand, if it comes from a difference in the preferences of households in which parents were child laborers, or different social norms associated with child labor experience, then the current theoretical child labor literature is not adequate to explain child labor in Brazil. Further research is needed to uncover this aspect of the persistence in child labor along with richer models.

Nonetheless, these results suggest that it might be better to treat households as a whole when it comes to designing policies aimed at reducing the incidence of child labor. These policies are important because in this paper we also show that child labor has harmful effects on individual's earnings abilities as adults. Thus the negative effect of the loss of educational attainment is greater than the positive effect of gaining experience as a child laborer. 
This paper has shown that the overall harmful effects of child labor extend well beyond the childhood years. The same child laborer as an adult does worse than a person who was not a child laborer, and that child laborer is much more likely to have to resort to sending his of her own child to work. Thus the cycle continues. It is important then to break this cycle within each household in order to achieve a lasting, long run reduction in child labor in a society. Policies that are able to break this cycle, family by family are potentially the most effective instrument to reduce the incidence of child labor. ${ }^{26}$ This type of policy might, for example, involve a one-time transfer of a critical level of resources to a family rather than continual general support of children's education. 
Table 1a: Unconditional Probabilities.

Child Working Strictly Positive Hours. Parent Began Working at age 14 or Below.

\begin{tabular}{|c|c|c|c|c|c|c|}
\hline \multirow{2}{*}{\multicolumn{2}{|c|}{$\begin{array}{l}\text { Son or Daughter is a } \\
\text { Child Laborer }\end{array}$}} & \multicolumn{2}{|c|}{ Father was a Child Laborer } & \multicolumn{2}{|c|}{ Mother was a Child Laborer } & \multirow[b]{2}{*}{ Total } \\
\hline & & No & Yes & No & Yes & \\
\hline \multirow{3}{*}{ No } & Number & 7991 & 16833 & 16708 & 8116 & 24824 \\
\hline & Row \% & 32.19 & 67.81 & 67.31 & 32.69 & 100 \\
\hline & Column \% & 94.1 & 82.72 & 92.19 & 75.72 & 86.07 \\
\hline \multirow{3}{*}{ Yes } & Number & 501 & 3517 & 1416 & 2602 & 4018 \\
\hline & Row \% & 12.47 & 87.53 & 35.24 & 64.76 & 100 \\
\hline & Column \% & 5.9 & 17.28 & 7.81 & 24.28 & 13.93 \\
\hline \multirow{3}{*}{ Total } & Number & 8492 & 20350 & 18124 & 10718 & 28842 \\
\hline & Row \% & 29.44 & 70.56 & 62.84 & 37.16 & 100 \\
\hline & Column \% & 100 & 100 & 100 & 100 & 100 \\
\hline
\end{tabular}

Table 1b: Unconditional Probabilities, Daughters Only.

Daughter Working Strictly Positive Hours. Parent Began Working at age 14 or Below.

\begin{tabular}{|c|c|c|c|c|c|c|}
\hline \multirow{2}{*}{$\begin{array}{l}\text { Daughter is a } \\
\text { Child Laborer }\end{array}$} & & \multicolumn{2}{|c|}{ Father was a Child Laborer } & \multicolumn{2}{|c|}{ Mother was a Child Laborer } & \multirow[b]{2}{*}{ Total } \\
\hline & & No & Yes & No & Yes & \\
\hline \multirow{3}{*}{ No } & Number & 4064 & 8908 & 8538 & 4434 & 12972 \\
\hline & Row \% & 31.33 & 68.67 & 65.82 & 34.18 & 100 \\
\hline & Column \% & 96.51 & 89.18 & 96.06 & 83.47 & 91.35 \\
\hline \multirow{3}{*}{ Yes } & Number & 147 & 1081 & 350 & 878 & 1228 \\
\hline & Row \% & 11.97 & 88.03 & 28.5 & 71.5 & 100 \\
\hline & Column \% & 3.49 & 10.82 & 3.94 & 16.53 & 8.65 \\
\hline \multirow{3}{*}{ Total } & Number & 4211 & 9989 & 8888 & 5312 & 14200 \\
\hline & Row \% & 29.65 & 70.35 & 62.59 & 37.41 & 100 \\
\hline & Column \% & 100 & 100 & 100 & 100 & 100 \\
\hline
\end{tabular}

Table 1c: Unconditional Probabilities, Sons Only.

Son Working Strictly Positive Hours. Parent Began Working at age 14 or Below.

\begin{tabular}{|c|c|c|c|c|c|c|}
\hline \multirow{2}{*}{$\begin{array}{l}\text { Son is a } \\
\text { Child Laborer }\end{array}$} & & \multicolumn{2}{|c|}{ Father was a Child Laborer } & \multicolumn{2}{|c|}{ Mother was a Child Laborer } & \multirow[b]{2}{*}{ Total } \\
\hline & & No & Yes & No & Yes & \\
\hline \multirow{3}{*}{ No } & Number & 3927 & 7925 & 8170 & 3682 & 11852 \\
\hline & Row \% & 33.13 & 66.87 & 68.93 & 31.07 & 100 \\
\hline & Column \% & 91.73 & 76.49 & 88.46 & 68.11 & 80.95 \\
\hline \multirow{3}{*}{ Yes } & Number & 354 & 2436 & 1066 & 1724 & 2790 \\
\hline & Row \% & 12.69 & 87.31 & 38.21 & 61.79 & 100 \\
\hline & Column \% & 8.27 & 23.51 & 11.54 & 31.89 & 19.05 \\
\hline \multirow{3}{*}{ Total } & Number & 4281 & 10361 & 9236 & 5406 & 14642 \\
\hline & Row \% & 29.24 & 70.76 & 63.08 & 36.92 & 100 \\
\hline & Column \% & 100 & 100 & 100 & 100 & 100 \\
\hline
\end{tabular}


Table 2: Child Labor Persistence. Probit on Child Labor Indicator Variable.

\begin{tabular}{|c|c|c|c|c|c|c|}
\hline Independent Variables & Coefficient & Std. Error & Coefficient & Std. Error & Coefficient & Std. Error \\
\hline Child Laborer Father & $0.333 * *$ & 0.029 & $0.259 * *$ & 0.030 & $0.251 * *$ & 0.039 \\
\hline Child Laborer Mother & $0.407 * *$ & 0.027 & $0.319 * *$ & 0.028 & $0.320 * *$ & 0.036 \\
\hline Father's Years of Schooling & & & $-0.028 * *$ & 0.004 & $-0.025 * *$ & 0.005 \\
\hline Mother's Years of Schooling & & & $-0.030 * *$ & 0.004 & $-0.033 * *$ & 0.005 \\
\hline Age of the Child & $0.208 * *$ & 0.008 & $0.211 * *$ & 0.008 & $0.214 * *$ & 0.010 \\
\hline $\begin{array}{l}\text { Years of Schooling of the } \\
\text { Grandfather (father's side) }\end{array}$ & & & & & 0.000 & 0.009 \\
\hline $\begin{array}{l}\text { Years of Schooling of the } \\
\text { Grandmother (father's side) }\end{array}$ & & & & & -0.008 & 0.009 \\
\hline $\begin{array}{l}\text { Years of Schooling of the } \\
\text { Grandfather (mother's side) }\end{array}$ & & & & & -0.001 & 0.008 \\
\hline Years of Schooling of the & & & & & & \\
\hline Grandmother (mother's side) & & & & & 0.002 & 0.009 \\
\hline Female Child & $-0.587 * *$ & 0.032 & $-0.593 * *$ & 0.032 & $-0.587 * *$ & 0.042 \\
\hline Urban & $-0.842 * *$ & 0.023 & $-0.730 * *$ & 0.024 & $-0.736 * *$ & 0.030 \\
\hline Father not in the Labor Market & $-0.172 * *$ & 0.045 & $-0.236 * *$ & 0.046 & $-0.251 * *$ & 0.062 \\
\hline Mother not in the Labor Market & $-0.270 * *$ & 0.027 & $-0.361 * *$ & 0.029 & $-0.361 * *$ & 0.036 \\
\hline Father's Age & $0.008 * *$ & 0.002 & $0.005 * *$ & 0.002 & 0.002 & 0.002 \\
\hline Mother's Age & 0.003 & 0.002 & 0.000 & 0.002 & 0.003 & 0.003 \\
\hline Number of Boys Aged 0 to 5 & 0.059 & 0.022 & 0.033 & 0.022 & 0.001 & 0.029 \\
\hline Number of Boys Aged 6 to 9 & $0.118 * *$ & 0.020 & $0.087 * *$ & 0.020 & $0.063 *$ & 0.027 \\
\hline Number of Boys Aged 10 to 14 & $0.085 * *$ & 0.018 & $0.059 * *$ & 0.018 & 0.040 & 0.022 \\
\hline Number of Boys Aged 15 to 17 & 0.036 & 0.020 & 0.012 & 0.020 & 0.038 & 0.026 \\
\hline Number of Girls Aged 0 to 5 & $0.126 * *$ & 0.021 & $0.096 * *$ & 0.021 & $0.128 * *$ & 0.027 \\
\hline Number of Girls Aged 6 to 9 & $0.122 * *$ & 0.020 & $0.092 * *$ & 0.020 & $0.109 * *$ & 0.025 \\
\hline Number of Girls Aged 10 to 14 & $0.078 * *$ & 0.018 & $0.049 * *$ & 0.018 & 0.028 & 0.023 \\
\hline Number of Girls Aged 15 to 17 & -0.022 & 0.023 & -0.040 & 0.023 & -0.043 & 0.029 \\
\hline Constant & $-3.871 * *$ & 0.119 & $-3.255 * *$ & 0.124 & $-3.245 * *$ & 0.159 \\
\hline Number of Observations & \multicolumn{2}{|c|}{28,805} & \multicolumn{2}{|c|}{28,665} & \multicolumn{2}{|c|}{17,687} \\
\hline Chi-Squared (n) & \multicolumn{2}{|c|}{$4018.73(17)$} & \multicolumn{2}{|c|}{ 4094.19(19) } & \multicolumn{2}{|c|}{$2542.85(23)$} \\
\hline Psuedo R-squared & \multicolumn{2}{|c|}{0.230} & \multicolumn{2}{|c|}{0.242} & \multicolumn{2}{|c|}{0.248} \\
\hline
\end{tabular}

* Statistically significant at the 5\% level. ** Statistically significant at the $1 \%$ level.

White's heteroskedastic consistent errors used in all regressions. 
Table 3: Child Labor Persistence.

Probit on Child Labor Indicator Variable Including Family Income as Explanatory Variable.

\begin{tabular}{|c|c|c|c|c|}
\hline Independent Variables & Coefficient & Std. Error & Coefficient & Std. Error \\
\hline Child Laborer Father & $0.258 * *$ & 0.031 & $0.310^{* *}$ & 0.030 \\
\hline Child Laborer Mother & $0.319 * *$ & 0.028 & $0.369^{* *}$ & 0.028 \\
\hline Father's Years of Schooling & $-0.026 * *$ & 0.004 & & \\
\hline Mother's Years of Schooling & $-0.028 * *$ & 0.004 & & \\
\hline Age of the Child & $0.212 * *$ & 0.008 & $0.211 * *$ & 0.008 \\
\hline Female Child & $-0.583 * *$ & 0.033 & $-0.578 * *$ & 0.033 \\
\hline Urban & $-0.718 * *$ & 0.024 & $-0.783 * *$ & 0.024 \\
\hline Father not in the Labor Market & $-0.244 * *$ & 0.046 & $-0.230 * *$ & 0.046 \\
\hline Mother not in the Labor Market & $-0.363 * *$ & 0.029 & $-0.314 * *$ & 0.028 \\
\hline Father's Age & $0.005^{* *}$ & 0.002 & $0.008 * *$ & 0.002 \\
\hline Mother's Age & 0.001 & 0.002 & 0.003 & 0.002 \\
\hline Number of Boys Aged 0 to 5 & 0.037 & 0.022 & $0.052 *$ & 0.022 \\
\hline Number of Boys Aged 6 to 9 & $0.081 * *$ & 0.021 & $0.101^{* *}$ & 0.021 \\
\hline Number of Boys Aged 10 to 14 & $0.058 * *$ & 0.018 & $0.073^{* *}$ & 0.018 \\
\hline Number of Boys Aged 15 to 17 & 0.011 & 0.021 & 0.032 & 0.021 \\
\hline Number of Girls Aged 0 to 5 & $0.095 * *$ & 0.022 & $0.115^{* *}$ & 0.022 \\
\hline Number of Girls Aged 6 to 9 & $0.095 * *$ & 0.020 & $0.113^{* *}$ & 0.020 \\
\hline Number of Girls Aged 10 to 14 & $0.047 * *$ & 0.018 & $0.065^{* *}$ & 0.018 \\
\hline Number of Girls Aged 15 to 17 & -0.030 & 0.024 & -0.015 & 0.023 \\
\hline Family Income minus Child Income & -0.00002 & 0.00002 & $-0.00012 * *$ & 0.00002 \\
\hline Constant & $-3.311 * *$ & 0.126 & $-3.797 * *$ & 0.121 \\
\hline Number of Observations & \multicolumn{2}{|c|}{27791} & \multicolumn{2}{|c|}{27926} \\
\hline Chi-Squared (n) & \multicolumn{2}{|c|}{$3935.88(20)$} & \multicolumn{2}{|c|}{$3837.11(18)$} \\
\hline Psuedo R-squared & \multicolumn{2}{|c|}{0.2384} & \multicolumn{2}{|c|}{0.2308} \\
\hline
\end{tabular}

* Statistically significant at the 5\% level. ** Statistically significant at the $1 \%$ level.

White's heteroskedastic consistent errors used in all regressions. 
Table 4: Survival Function: Number of Years Between Birth and Entering Labor Market.

\begin{tabular}{cccccc}
\hline Time & Beg. Total & Fail & Net Lost & Survival Function & Std. Error \\
\hline 4 & 28847 & 5 & 0 & 0.9998 & 0.0001 \\
5 & 28842 & 41 & 0 & 0.9984 & 0.0002 \\
6 & 28801 & 105 & 0 & 0.9948 & 0.0004 \\
7 & 28696 & 260 & 0 & 0.9858 & 0.0007 \\
8 & 28436 & 594 & 0 & 0.9652 & 0.0011 \\
9 & 27842 & 754 & 0 & 0.939 & 0.0014 \\
10 & 27088 & 1153 & 5329 & 0.8991 & 0.0018 \\
11 & 20606 & 472 & 5009 & 0.8785 & 0.002 \\
12 & 15125 & 545 & 4823 & 0.8468 & 0.0023 \\
13 & 9757 & 385 & 4713 & 0.8134 & 0.0028 \\
14 & 4659 & 228 & 4431 & 0.7736 & 0.0037 \\
\hline
\end{tabular}

Table 5: Child Labor Persistence. Cox Proportional Hazard Model on Number of Years between Birth and Entering Labor Market.

\begin{tabular}{|c|c|c|c|c|c|c|}
\hline Independent Variables & Hazard Ratio & Std. Error & Hazard Ratio & Std. Error & Hazard Ratio & Std. Error \\
\hline Child Laborer Father & $1.883^{* *}$ & 0.090 & $1.656 * *$ & 0.081 & $1.636^{* *}$ & 0.105 \\
\hline Child Laborer Mother & $2.063^{* *}$ & 0.084 & $1.806^{* *}$ & 0.076 & $1.827 * *$ & 0.097 \\
\hline Father's Years of Schooling & & & $0.958^{* *}$ & 0.006 & $0.966^{* *}$ & 0.008 \\
\hline Mother's Years of Schooling & & & $0.943^{* *}$ & 0.006 & $0.942 * *$ & 0.008 \\
\hline $\begin{array}{l}\text { Years of Schooling of the Grandfather } \\
\text { (father's side) }\end{array}$ & & & & & 0.996 & 0.014 \\
\hline $\begin{array}{l}\text { Years of Schooling of the Grandmother } \\
\text { (father's side) }\end{array}$ & & & & & 0.982 & 0.014 \\
\hline $\begin{array}{l}\text { Years of Schooling of the Grandfather } \\
\text { (mother's side) }\end{array}$ & & & & & 0.997 & 0.013 \\
\hline $\begin{array}{l}\text { Years of Schooling of the Grandmother } \\
\text { (mother's side) }\end{array}$ & & & & & 1.001 & 0.014 \\
\hline Female Child & $0.419 * *$ & 0.019 & $0.420 * *$ & 0.019 & $0.426^{* * *}$ & 0.024 \\
\hline Urban & $0.295^{* *}$ & 0.009 & $0.358^{* *}$ & 0.012 & $0.347^{* *}$ & 0.014 \\
\hline Father not in the Labor Market & 0.927 & 0.061 & $0.852 *$ & 0.057 & $0.782 * *$ & 0.073 \\
\hline Mother not in the Labor Market & $0.744 * *$ & 0.031 & $0.660^{* *}$ & 0.029 & $0.658^{* *}$ & 0.036 \\
\hline Father's Age & $1.009^{* *}$ & 0.002 & 1.004 & 0.002 & 1.002 & 0.003 \\
\hline Mother's Age & $1.006^{*}$ & 0.003 & 1.002 & 0.003 & 1.006 & 0.004 \\
\hline Number of Boys Aged 0 to 5 & $1.069 *$ & 0.031 & 1.027 & 0.030 & 0.986 & 0.039 \\
\hline Number of Boys Aged 6 to 9 & $1.146^{* *}$ & 0.033 & $1.094 * *$ & 0.031 & 1.037 & 0.038 \\
\hline Number of Boys Aged 10 to 14 & $1.138^{* *}$ & 0.027 & $1.102 * *$ & 0.026 & $1.090^{* * *}$ & 0.032 \\
\hline Number of Boys Aged 15 to 17 & 1.045 & 0.029 & 1.008 & 0.028 & 1.043 & 0.037 \\
\hline Number of Girls Aged 0 to 5 & $1.177^{* *}$ & 0.034 & $1.130^{* *}$ & 0.032 & $1.200^{* *}$ & 0.044 \\
\hline Number of Girls Aged 6 to 9 & $1.163 * *$ & 0.031 & $1.1088 * *$ & 0.0292 & $1.151^{* * *}$ & 0.039 \\
\hline Number of Girls Aged 10 to 14 & $1.115^{* *}$ & 0.027 & $1.0631 *$ & 0.0260 & $1.040 *$ & 0.033 \\
\hline Number of Girls Aged 15 to 17 & 0.973 & 0.031 & 0.9447 & 0.0304 & 0.927 & 0.038 \\
\hline Number of Observations & \multicolumn{2}{|c|}{28,807} & \multicolumn{2}{|c|}{28,667} & \multicolumn{2}{|c|}{17,687} \\
\hline Chi-Squared (n) & \multicolumn{2}{|c|}{$4987.89(16)$} & \multicolumn{2}{|c|}{$5215.85(18)$} & \multicolumn{2}{|c|}{$3273.35(22)$} \\
\hline
\end{tabular}

* Statistically significant at the 5\% level. ** Statistically significant at the $1 \%$ level.

White's heteroskedastic consistent errors used in all regressions. 
Table 6: Effect of Child Labor on Log of Adult Earnings of Fathers and Mothers. OLS and Heckman Model Estimates.

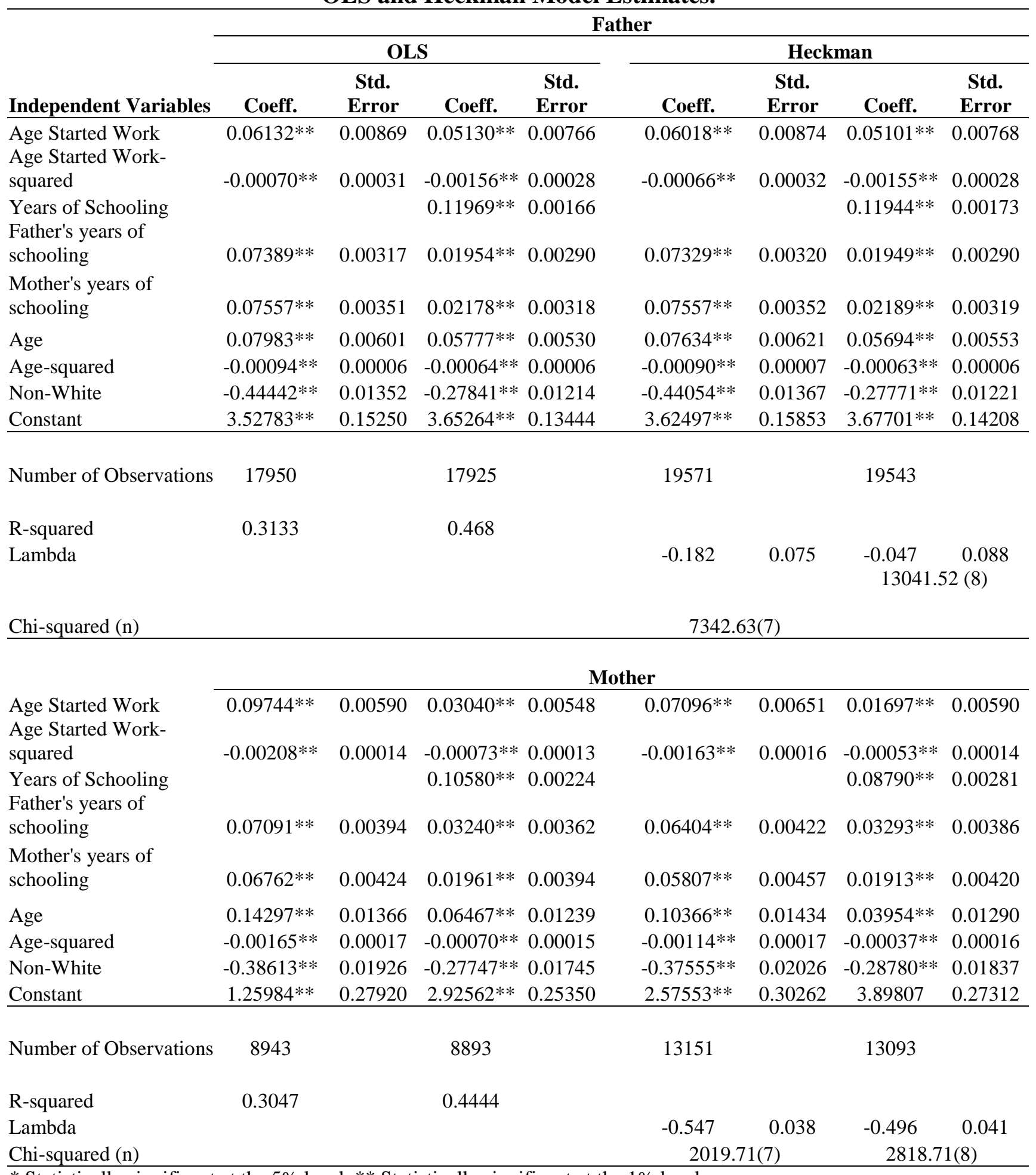

* Statistically significant at the 5\% level. ** Statistically significant at the $1 \%$ level.

White's heteroskedastic consistent errors used in all regressions. 
Appendix A: Sample Statistics of the Variables used in the Empirical Analysis.

\begin{tabular}{|c|c|c|c|c|c|}
\hline Children's Variables & Obs & Mean & Std. Dev. & Min & Max \\
\hline$\overline{\text { Age }}$ & 28847 & 12.011 & 1.421 & 10 & 14 \\
\hline Female indicator variable & 28847 & 0.492 & 0.500 & 0 & 1 \\
\hline Hours & 28842 & 3.763 & 10.796 & 0 & 98 \\
\hline Working strictly positive hours indicator variable & 28842 & 0.139 & 0.346 & 0 & 1 \\
\hline Working at least 20 hours per week indicator variable & 28842 & 0.105 & 0.306 & 0 & 1 \\
\hline Urban indicator variable & 28847 & 0.774 & 0.418 & 0 & 1 \\
\hline Schooling indicator variable & 28841 & 0.925 & 0.263 & 0 & 1 \\
\hline Only school indicator variable & 28,841 & 0.822 & 0.383 & 0 & 1 \\
\hline School and work indicator variable & 28,836 & 0.102 & 0.303 & 0 & 1 \\
\hline Only work indicator variable & 28,842 & 0.024 & 0.153 & 0 & 1 \\
\hline No school, no work indicator variable & 28,836 & 0.050 & 0.218 & 0 & 1 \\
\hline Years of schooling & 28830 & 3.341 & 1.946 & 0 & 9 \\
\hline Age started work & 4542 & 10.055 & 1.997 & 4 & 14 \\
\hline \multicolumn{6}{|l|}{ Fathers' variables } \\
\hline Age & 28847 & 43.824 & 9.225 & 25 & 98 \\
\hline Years of schooling & 28801 & 4.920 & 4.559 & 0 & 17 \\
\hline Age started work & 27125 & 12.134 & 3.688 & 4 & 40 \\
\hline Earnings & 28300 & 521.001 & 905.135 & 0 & 40000 \\
\hline Child labor (age 14 or below) & 28847 & 0.706 & 0.456 & 0 & 1 \\
\hline Child labor (age 10 or below) & 28847 & 0.394 & 0.489 & 0 & 1 \\
\hline Not in labor market & 28814 & 0.100 & 0.300 & 0 & 1 \\
\hline \multicolumn{6}{|l|}{ Mothers' variables } \\
\hline Age & 28847 & 39.602 & 7.748 & 25 & 91 \\
\hline Years of schooling & 28744 & 5.035 & 4.375 & 0 & 17 \\
\hline Age started work & 17075 & 13.900 & 5.784 & 4 & 56 \\
\hline Earnings & 28710 & 143.869 & 445.588 & 0 & 20000 \\
\hline Child labor (age 14 or below) & 28847 & 0.372 & 0.483 & 0 & 1 \\
\hline Child labor (age 10 or below) & 28847 & 0.203 & 0.402 & 0 & 1 \\
\hline Not in labor market & 28831 & 0.462 & 0.499 & 0 & 1 \\
\hline \multicolumn{6}{|l|}{ Grandparents' variables: } \\
\hline Years of schooling of the grandfather (father's side) & 22085 & 2.016 & 2.949514 & 0 & 17 \\
\hline Years of schooling of the grandmother (father's side) & 23813 & 1.707 & 2.649685 & 0 & 17 \\
\hline Years of schooling of the grandfather (mother's side) & 23470 & 2.075 & 2.879995 & 0 & 17 \\
\hline Years of schooling of the grandmother (mother's side) & 25059 & 1.744 & 2.618133 & 0 & 17 \\
\hline \multicolumn{6}{|l|}{ Families' variables: } \\
\hline Number of Boys Aged 0 to 5 & 28847 & 0.195 & 0.471 & 0 & 5 \\
\hline Number of Boys Aged 6 to 9 & 28847 & 0.267 & 0.514 & 0 & 4 \\
\hline Number of Boys Aged 10 to 14 & 28847 & 0.863 & 0.771 & 0 & 4 \\
\hline Number of Boys Aged 15 to 17 & 28847 & 0.252 & 0.495 & 0 & 3 \\
\hline Number of Girls Aged 0 to 5 & 28847 & 0.191 & 0.469 & 0 & 5 \\
\hline Number of Girls Aged 6 to 9 & 28847 & 0.266 & 0.515 & 0 & 3 \\
\hline Number of Girls Aged 10 to 14 & 28847 & 0.835 & 0.763 & 0 & 5 \\
\hline Number of Girls Aged 15 to 17 & 28847 & 0.209 & 0.455 & 0 & 4 \\
\hline
\end{tabular}




\section{Notes}

${ }^{1}$ For a useful survey of the both the theoretical and empirical literature, see Kaushik Basu "Child Labor:
Cause, Consequence, and Cure," Journal of Economic Literature 37, no. 3 (1999): 1083-1119.
2 See for example, Jean-Marie Baland and James A. Robinson. "Is Child Labor Inefficient?," Journal of
Political Economy 108, no. 4 (2000): 663-679; Basu (1999); Clive Bell and Hans Gersbach, "Child Labor
and the Education of a Society." Mimeo, (2000); Luis Felipe Lopez-Calva and Koji Miyamoto, "Filial
Obligations, Technology, and Child Labor," Centro de Estudios Economicos, El Colegio de Mexico,
Documento de Trabajo III-2000, (2000); Priya Ranjan, "Credit Constraints and the Phenomenon of Child
Labor," Journal of Development Economics 64, no. 1 (2001): 81-102. This is also closely linked to the
idea of poverty traps like that illustrated in Oded Galor and Joseph Zeira, "Income Distribution and
Macroeconomics," Review of Economic Studies 60, no.1 (1993): 35-52.
${ }^{3}$ See, for example, Ranjan Ray, "Analysis of Child Labour in Peru and Pakistan: A Comparative Study," ${ }^{3}$ See, for example, Ranjan Ray, "Analysis of Child Labour in Peru and Pakistan: A Comparative Study,"
Journal of Population Economics 13, no.1 (2000): 3-19, and "Child Labor, Child Schooling and their Interaction with Adult Labour: The Empirical Evidence and Some Analytical Implications," World Bank Economic Review, 14, no.2 (2000): 347-67; Peter Jensen and Helena Skyt Neilsen, "Child Labour or School Attendance? Evidence from Zambia," Journal of Population Economics 10, no.4 (1997): 407-424; Harry Anthony Patrinos and George Psacharopoulos, "Family Size, Schooling and Child Labor in Peru An Empirical Analysis," Journal of Population Economics 10, no.4 (1997): 387-405; George Psacharopoulos, "Child Labor Versus Educational Attainment: Some Evidence from Latin America," Journal of Population Economics 10, no.4 (1997): 377-386; and Christian Grootaert and Ravi Kanbur, "Child Labor: An Economic Perspective," International Labour Review 134, no.2 (1995): 187-203.

${ }^{4}$ Kaushik Basu and Pham Hoang Van, "The Economics of Child Labor," American Economic Review 88, no.3 (1998): 412-427.

${ }^{5}$ Ibid.

${ }^{6}$ Ibid.

${ }^{7}$ This is, of course, not always necessarily true. Children may make their own decisions if they are homeless, orphaned, runaways or particularly independent. See, for example, Jane Humphries, "Cliometrics, Child Labor, and the Industrial Revolution," Critical Revie 13, nos. 3-4 (1999): 269-283.

${ }^{8}$ This model is related to the model of household education choice developed Gerhard Glomm, "Parental Choice of Human Capital Investment," Journal of Development Economics 53, no.1 (1997): 99-114.

${ }^{9}$ This assumption follows in the tradition of Gary Becker's theory of the family: Gary Becker, Treatise on the Family. (Cambridge, MA: Harvard University Press, 1982).

${ }^{10}$ This assumes, of course, that the wage rate is unaffected by the supply of skilled labor. This is a strong assumption but the essential results would not change if we made the wage a function of skilled labor supply.

${ }^{11}$ Ranjan (2000).

${ }^{12}$ One could alternately assume that education choice is "lumpy," meaning that parents consider education to be a choice of literacy, primary education or high school diploma.

${ }^{13}$ PNAD assigns each individual to a position or 'condition' in the family. They are: (i) person of reference; (ii) spouse; (iii) son or daughter; (iv) other relative; (v) aggregate; (vi) pensionist; (vii) domestic worker; and (viii) relative of the domestic worker.

${ }^{14}$ This selection criterion may impose some selection bias if, for example, children in single head families are more likely to work. However, similar results were obtained when a full sample of 10 to 14 years old children were used. In this case the head of the family's characteristics were used instead of the father and mother's characteristics. Since we want to capture separate impacts of the father and the mother's child labor status and to have a straight interpretation of the coefficients, we present the results with the sample described in the text. Probit results with this alternative sample are available upon request.

${ }^{15}$ PNAD asks the usual hours worked per week for each individual working during the survey week.

${ }^{16}$ All results presented in this paper come from the un-weighted sample. We replicated all of the empirical tests in this paper using a weighted sample and obtained qualitatively the same results.

${ }^{17}$ See Christian Grootaert and Harry Anthony Patrinos, eds., Policy Analysis of Child Labor: A Comparative Study. (New York: St. Martin's Press, 1999).

${ }^{18}$ Ibid.

${ }^{19}$ The selection of a binary choice model is natural since we are interested in obtaining the probability of a child working in the labor force. We opt for a non-linear regression model because such models are better 
suited for the case where the dependent variable is clustered either in zero or one. The most common of these are the probit and logit models. The probit model assumes that the error term is standard-normally distributed and the logit model assumes the error term follows the logistic distribution. Because the cumulative normal distribution and the logistic distribution are very close to each other, except at the tails, we are not very likely to get different results, therefore we feel that both models are equally suited to estimate the predicted probability of a child working as a laborer. As a check of this assumption, we estimated both models and found that the results were qualitatively the same. In this paper, we present the results we obtained from estimating the probit model. For readers interested in the results we obtained from estimating the logit specification, they are available upon request.

${ }^{20}$ The inclusion of the indicator variables of a parent not in the labor market accounts for the fact that for those parents not in the labor market, the age started to work is unknown.

${ }^{21}$ Similar model was estimated for the case when child labor is defined as a child that worked at least 20 hours in the week of reference. We obtained qualitatively the same results.

${ }^{22}$ In our sample, roughly 10 percent of men and 46 percent of women were not in the labor market. There seems to be no reason, a priori, to think that these individuals would be more or less likely to have been child laborers. However, the fact is that we do not observe the child labor history of those not in the labor market. Hence for those we assign the parent child labor status equal zero. In order to control for potential bias that this assignment may create, we also introduce a dummy variable equal one for those parents that are not in the labor market. Still, in the extreme case where they all were child laborers, the negative and significant sign on the not in the labor market variables for fathers and mothers could counteract the positive coefficient on the parental child labor variable and could mean that the net effect of child labor status is insignificant. As only 10 percent of fathers are not in the labor market, it seems very unlikely that this would be the case, but it is potentially a problem for the effect of maternal child labor.

${ }^{23}$ PNAD 1996 presents the educational attainment of the grandparents in ten categories. We converted these categories into years of schooling in the following way:

\section{Category}

No school or incomplete first grade, first grade degree

Years of Schooling
0
2
4
6
8
9.5
11
13
15
17

Complete elementary or complete fourth grade, first grade degree

Incomplete half first cycle or fifth to seventh grade, first grade degree

Complete half first cycle or complete eighth grade, first grade degree

Incomplete half second cycle or incomplete second grade degree

Complete half second cycle or complete second grade degree

Incomplete superior

Complete superior

Complete master or doctorate

${ }^{24}$ For an excellent summary of duration models, and particularly the Cox proportional hazard model, see Nicholas Kiefer, "Economic Duration Data and Hazard Functions," Journal of Economic Literature 26, no.2 (1988): 646-679.

${ }^{25} \mathrm{We}$ assume to be child laborer those respondents that reported an age at which they entered the labor force. In some cases we have observations on children who were not working during the reference week, but nevertheless reported an age at which they entered the labor force. To check robustness we also estimated the same model considering only the children that reported the age that they started working and were working in the week of reference as a child laborer. The results were qualitatively the same.

${ }^{26}$ Bell and Gersbach (2000) present an excellent analysis of exactly this type of government plan. 